\title{
O CURSO TÉCNICO A DISTÂNCIA EM AGRICULTURA E O DESENVOLVIMENTO RURAL DOS MUNICÍPIOS DE CANGUÇU E DE SÃO LOURENÇO DO SUL - RIO GRANDE DO SUL
}

\author{
Lilianna Bolsson Loebler ${ }^{1}$ \\ Rosane Bernardete Brochier Kist ${ }^{2}$ \\ Cidonea Machado Deponti ${ }^{3}$ \\ Marco André Cadoná ${ }^{4}$ iD
}

\section{Resumo}

Este artigo objetiva analisar as implicações do Curso Técnico em Agricultura, integrante do Programa e-Tec Brasil, para a formação de agricultores e para o desenvolvimento da agricultura nos municípios de São Lourenço do Sul e de Canguçu. Realizou-se um estudo de enfoque qualitativo, com base no método dialético crítico, da qual foram realizadas entrevistas semiestruturadas com 22 alunos dos Polos de Canguçu e de São Lourenço do Sul, e com 19 profissionais do Campus de Alegrete, integrantes de um Curso em Agricultura na modalidade a distância, ofertado na região sul do Brasil. A análise dos dados ocorreu através da técnica de análise de conteúdo e da técnica de tratamento estatístico simples. Constatou-se que o Curso Técnico em Agricultura na modalidade a Distância possui um papel importante no processo de desenvolvimento da agricultura dos municípios analisados, pois possibilita a permanência dos alunos em seus municípios de origem, o processo de qualificação das

\footnotetext{
${ }^{1}$ Mestre em Ciência e Tecnologia de Sementes, Doutora em Desenvolvimento Regional (UNISC), Professora do Instituto de Ciência e Tecnologia Farroupilha, RS, Rua: Dr. Bozano, 629/602. Endereço: Bairro Bom Fim. Camobi. Santa Maria-RS, Brasil. CEP 97015000. E-mail: lilianna.loebler@iffarroupilha.edu.br

2 Mestre e Doutora em Serviço Social (PUCRS), Pós-Doutoranda Bolsista DOCFIX (CAPES/FAPERGS), Professora do Programa de Pós-graduação em Desenvolvimento Regional (UNISC). Endereço: Rua Augusto Spengler, 897/306. Bairro Universitário - Santa Cruz do Sul, RS, Brasil. CEP 96820020, RS. E-mail: rosanekist@unisc.br

3 Mestre em Integração Latino-Americana (UFSM), Doutora em Desenvolvimento Rural (UFRGS), PósDoutorado em Sociologia do Desenvolvimento (UFRGS), Professora Programa de Pós-Graduação em Desenvolvimento Regional (UNISC). Endereço: Rua: Jacob Carlos Lampert, 60, Bairro São João, MontenegroRS.CEP 95780000. E-mail: cidonea@unisc.br

${ }^{4}$ Mestre em Sociologia (UFRGS), Doutor em Sociologia Política (UFSC, Professor Programa de PósGraduação em Desenvolvimento Regional (UNISC). Endereço: Rua: Av. Independência, 2293. Bloco 10. Sala 1023 Bairro Universitário. Santa Cruz do Sul, RS, Brasil. CEP 96815900. E-mail: mcadona@ unisc.br
} 
O CURSO TÉCNICO A DISTÂNCIA EM AGRICULTURA E O DESENVOLVIMENTO RURAL DOS MUNICÍPIOS DE CANGUÇU E DE SÃO LOURENÇO DO SUL - RIO GRANDE DO SUL

propriedades rurais e a ascensão profissional desses sujeitos através de oportunidades de ingresso no mercado de trabalho (no setor privado e/ou a partir do poder público).

Palavras-chave: Curso Técnico em Agricultura; Educação a Distância; Desenvolvimento Rural; Qualificação Profissional; Agricultura Familiar

\section{INTRODUÇÃO}

Identifica-se que nas últimas décadas a Educação tem sido destacada como uma estratégia importante para o desenvolvimento do país. Por outro lado, se reconhece que somente o acesso à educação não garante a permanência e a conclusão da formação de todos os sujeitos de uma forma equitativa, além de que, nem todas as pessoas possuem esse direito efetivado. Da mesma forma, percebe-se a existência de lacunas no processo formativo em decorrência de vários fatores relacionados especialmente com as condições objetivas de vida dos sujeitos e com as dificuldades encontradas pelos profissionais da educação, que evidenciam fragilidades decorrentes de sua própria formação profissional, da falta de seu reconhecimento e valorização, bem como das estruturas físicas precárias e ineficientes para garantirem uma educação com qualidade.

Tendo em vista a expansão do acesso da população a índices mais elevados de alfabetização e de qualificação profissional, especialmente a partir da Lei de Diretrizes e Bases da Educação Nacional (BRASIL, 1996) foram estabelecidas bases legais para a Educação a Distância no Brasil. Dessa forma, essa modalidade passou a ser reconhecida como uma estratégia de ensino aplicável ao sistema educacional brasileiro, visando à democratização do acesso à educação através do uso de tecnologias de informação e comunicação, da flexibilização dos espaços e do tempo de aprendizagem e de um processo de gestão integrada que articule atividades presenciais e a distância. Através do Decreto Presidencial número 5.622 (BRASIL, 2005, p. 1) a educação a Distância no Brasil passa a ser caracterizada como:

[...] modalidade educacional na qual a mediação didático-pedagógica nos processos de ensino e aprendizagem ocorre com a utilização de meios e tecnologias de informação e comunicação, com estudantes e professores desenvolvendo atividades educativas em lugares ou tempos diversos. (BRASIL, 2005, p. 1).

Entretanto, o reconhecimento da Educação a Distância como status de um sistema nacional ocorreu somente no ano de 2006, através do Decreto n ${ }^{\circ} 5.800$ (BRASIL, 2006), pelo 
LOEBLER, L. B.; KIST, R. B. B.; DEPONTI, C. M.; CADONÁ, M. A.

qual foi instituído o sistema Universidade aberta do Brasil (UAB), voltado para o desenvolvimento da Modalidade de Educação a Distância com a finalidade de expandir e interiorizar a oferta de cursos e programas de educação superior no país. O referido Decreto evidencia que a concretização das finalidades e dos objetivos socioeducacionais deve ocorrer em regime de colaboração envolvendo a União e os demais entes federativos, através da implementação de cursos e de programas de educação superior a distância desenvolvidos por instituições públicas de ensino superior, de forma articulada com os polos de apoio presencial.

Nessa perspectiva, no ano de 2008 o Governo Federal criou os Institutos Federais de Educação, Ciência e Tecnologia, através da Lei n ${ }^{\circ} 11.892$ (BRASIL, 2008), tendo em vista a oferta de educação de forma gratuita em regiões carentes de ensino profissional do país. No Estado do Rio Grande do Sul foram criados três Institutos Federais de Educação, Ciência e Tecnologia: o do Rio Grande do Sul (IFRS), o Sul Rio-Grandense (IFSul) e o Instituto Federal Farroupilha (IF Farroupilha), conforme Lei $n^{\circ}$ 11.892, de 2008 (BRASIL, 2008). De acordo com a referida Lei, uma das finalidades da criação dos Institutos Federais consiste em

[...] ofertar educação profissional e tecnológica, em todos os seus níveis e modalidades, formando e qualificando cidadãos com vistas na atuação profissional nos diversos setores da economia, com ênfase no desenvolvimento socioeconômico local, regional e nacional (BRASIL, 2008, p. 5).

No ano de 2011, através do Decreto $\mathrm{n}^{\circ} 7.589$ (BRASIL, 2011), o Governo Federal criou, no âmbito do Ministério da Educação, a Rede e-Tec Brasil, com a finalidade de “[...] desenvolver a educação profissional e tecnológica na modalidade de educação a distância, ampliando e democratizando a oferta e o acesso à educação profissional pública e gratuita no País”. (BRASIL, 2011, p. 1). Dessa forma, foi revogado o Decreto nº 6.301 que havia instituído o "Sistema Escola Técnica Aberta do Brasil".

A Rede e-Tec Brasil integra o Plano Nacional de Desenvolvimento da Educação (PDE), sendo que os Polos do Sistema Escola Técnica Aberta do Brasil (e-Tec Brasil) são avaliados pelo Ministério da Educação. Através do Fundo Nacional de Educação, são disponibilizados recursos para capacitação dos professores e tutores para a realização dos processos seletivos, para despesas de infraestrutura e para a oferta dos cursos que possuem média de dois anos.

A Rede e-Tec Brasil segue o modelo da Universidade Aberta do Brasil (UAB), especialmente no que se refere ao funcionamento, à legislação e à estrutura de pessoal. Assim, o Sistema Rede e-Tec Brasil, através da articulação, interação e a efetivação de iniciativas que estimulam a parceria dos três níveis governamentais (federal, estadual e municipal) com 
as universidades públicas e demais organizações interessadas, busca a viabilização de mecanismos alternativos para o fomento, a implantação e a execução de cursos técnicos em parceria.

A partir do processo de implantação da Rede e-Tec Brasil, houve uma ampliação da abrangência do Instituto Federal Farroupilha no Estado do Rio Grande do Sul, especialmente nos anos de 2012 e de 2014. Esse processo ocorreu, também, em função da criação de novos Campus, de Polos EAD e de Centros de Referência, conforme previsto no Plano de Ação Institucional do Instituto Federal Farroupilha 2010-2012 (INSTITUTO FEDERAL FARROUPILHA, 2014). Assim, no ano de 2009, ocorreu a implantação dos polos de Educação a Distância nos municípios de Canguçu e de São Lourenço do Sul, ligados ao Instituto Federal Farroupilha.

Neste artigo aborda-se, inicialmente, o processo de implantação dos Polos de Educação a Distância nos municípios de Canguçu e de São Lourenço do Sul a partir do Instituto Federal Farroupilha. Na sequência, apresentam-se as características socioeconômicas dos alunos, seguidas das percepções dos mesmos sobre os benefícios do curso para suas vidas e a de suas famílias. No último item apresenta-se a relação existente entre o Curso a Distância e o Desenvolvimento Rural em Canguçu e São Lourenço do Sul. Ao final, apresentam-se algumas considerações sobre o tema.

\section{A IMPLANTAÇÃO DOS POLOS DE EDUCAÇÃO A DISTÂNCIA NOS MUNicíPIOS DE CANGUÇU E DE SÃo LOURENÇO do SUl A PARTIR do INSTITUTO FEDERAL FARROUPILHA}

O curso de agricultura em Educação na modalidade a Distância, objeto desta análise, integra o Instituto Federal Farroupilha, Campus de Alegrete. Ressalta-se que a instituição aderiu a esse projeto em Educação a Distância em função de sua preocupação com o atendimento de alunos que não tinham condições de frequentar os cursos presenciais, especialmente aqueles que vivem no meio rural. Dessa forma, buscou-se, através do Curso Técnico em Agricultura na modalidade a Distância, promover o acesso à educação, à tecnologia, à pesquisa e à extensão para os alunos da zona rural, moradores de municípios predominantemente agrícolas, que se encontravam distantes geograficamente do campus e que apresentavam dificuldades financeiras para frequentar as aulas presenciais, além de 
LOEBLER, L. B.; KIST, R. B. B.; DEPONTI, C. M.; CADONÁ, M. A.

apresentarem interesse em frequentar um curso na área agrícola, visando ao desenvolvimento de suas propriedades rurais.

No ano de 2009 foi realizado o primeiro processo seletivo de estudantes para os cursos EAD nos municípios avaliados e aprovados pelo $\mathrm{MEC}^{5}$. A partir do Instituto Federal Farroupilha, iniciou-se uma pareceria envolvendo o Governo Federal, as Instituições de Ensino e os seguintes municípios: Alegrete, São Borja, Canguçu, Bagé, Santa Maria, Santo Antônio da Patrulha e São Lourenço do Sul. No período de 2010 a 2012 novos municípios aderiram ao programa obtendo autorização e credenciamento diretamente junto ao Ministério de Educação e Cultura. A partir de 2012, o Governo Federal descentralizou essa abertura de polos aos Institutos Federais de Educação, o que proporcionou uma rápida expansão de polos de Educação a Distância também em nível nacional.

O Ministério de Educação e Cultura (MINISTÉRIO DA EDUCAÇÃO E CULTURA, 2015) define Polo de Educação a Distância ou Polo de Apoio Presencial como o local devidamente autorizado, no país ou no exterior, para o desenvolvimento descentralizado de atividades pedagógicas e administrativas relativas aos cursos e programas ofertados a distância. Assim, os polos de Educação a Distância nos municípios de Canguçu e São Lourenço do Sul foram criados com a finalidade de constituírem-se como núcleos de apoio pedagógico e administrativo do sistema Rede e-Tec Brasil. Para tanto, foi constituída uma estrutura física básica que contempla biblioteca, laboratórios de informática, salas de tutoria presencial, salas para as aulas presenciais, práticas de laboratório, dentre outras atividades necessárias ao andamento dos cursos.

Os Polos EAD de Canguçu e de São Lourenço do Sul abrigam cursos que são ofertados por diferentes instituições que, de forma partilhada, utilizam a mesma estrutura física e estão sob a abrangência da mesma coordenação de polo. Dessa forma, os recursos do Fundo Nacional de Desenvolvimento da Educação (FNDE) são disponibilizados para a Instituição ofertante com base em um Plano de Trabalho Anual (PTA) que prevê o pagamento de coordenadores, de professores, de tutores, a aquisição do material didático, do material bibliográfico e do material de consumo utilizados para a realização das aulas presenciais e online, além de diárias destinadas aos encontros presenciais com os professores do curso.

Os recursos para pagamento dos professores, dos tutores e dos coordenadores são provenientes de bolsas oriundas do FNDE. O número de alunos para atendimento é definido

$5 \quad$ Além do Instituto Federal Farroupilha, outras Instituições de Ensino Federal também participaram do início do programa no Rio Grande do Sul, como a Universidade Federal do Rio Grande do Sul (UFRGS), a Universidade Federal de Santa Maria (UFSM) e a Universidade Federal de Pelotas (UFPEL), através de suas escolas técnicas. 
pelo PTA, sendo que cada tutor presencial deve atender 40 alunos. O coordenador de polo é indicado pela Prefeitura Municipal, constituindo-se como um "cargo de confiança"; entretanto, seu ingresso somente ocorre mediante a concordância da instituição.

Esses profissionais são os que atuam diretamente com os alunos, de forma presencial no polo EAD, para assessorá-los nas dificuldades e acompanhá-los nas atividades. Para isto, têm como principal função o auxílio na resolução das dificuldades encontradas de modo a garantir que o aluno receba a assistência devida e que sejam tomadas as providências necessárias pelo coordenador de curso, pelos professores e tutores que atuam junto ao Núcleo de Educação a Distância (NEAD), localizado no referido campus.

Para a realização deste estudo foram entrevistados 19 profissionais que atuam junto ao Campus de Alegrete. São eles: cinco professores; seis coordenadores (um coordenador de Núcleo de Ensino a Distância: um coordenador Geral da Rede e-Tec; dois Coordenadores de Tutoria e dois coordenadores de Polo); dois Supervisores Pedagógicos; seis Tutores (três Tutores Presenciais e três Tutores a Distância) ${ }^{1}$. Foram entrevistados, também, 22 alunos dos Polos de Canguçu e de São Lourenço do Sul.

\section{CARACTERÍSTICAS SOCIOECONÔMICAS DOS ALUNOS}

Para a realização deste estudo foram entrevistados 22 alunos que frequentam os Polos presenciais de Canguçu e de São Lourenço do Sul, sendo que 10 deles foram entrevistados no Polo de Canguçu e 12 no Polo de São Lourenço do Sul. O levantamento de dados sobre as características socioeconômicas dos alunos ocorreu através de pesquisa documental no Núcleo de Ensino a Distância (NEAD) do campus ofertante do curso, da qual foi possível obter informações sobre a faixa etária, o sexo, a cor, o estado civil e as condições familiares dos mesmos. Foram analisados dados das fichas de matrícula de 230 alunos integrantes das turmas de 2009 a 2012, do IF Farroupilha, nos polos de São Lourenço do Sul e de Canguçu.

Os dados apresentados no Gráfico 1 evidenciam que os alunos de faixas etárias mais jovens, com idades até 20 anos, representam a minoria, pois correspondem a apenas $3,48 \%$ do total de alunos matriculados. Essa baixa procura de alunos nessa faixa etária pode ser ocasionada pelo fato de muitos deles se deslocarem para outras cidades para cursarem um curso superior ou, ainda, porque muitos nem mesmo concluíram o Ensino Fundamental, seja por problemas econômicos ou por falta de motivação para o estudo. 
LOEBLER, L. B.; KIST, R. B. B.; DEPONTI, C. M.; CADONÁ, M. A.

Por outro lado, identifica-se que a maioria dos alunos possui idades entre 21 e 40 anos, o que representa um percentual de $72,07 \%$ do total de alunos matriculados no período analisado. Entretanto, a concentração maior de alunos, considerando-se todo o grupo, encontra-se na faixa etária entre 21 a 30 anos, que corresponde a 40,87\% do total de alunos.

Os dados apresentados demonstram que no Curso em Agricultura na modalidade a distância existe um predomínio de alunos com perfil de adultos, com faixas etárias que possibilitam, em geral, a plena capacidade produtiva de trabalho. O Gráfico 2 evidencia que há uma maior quantidade de alunos do sexo masculino, que correspondem a 73,91\% do total de alunos matriculados. Esses dados podem ser explicados pelo fato de o curso analisado ser na área da agricultura, na qual, culturalmente, muitas das atividades são desempenhadas por homens.

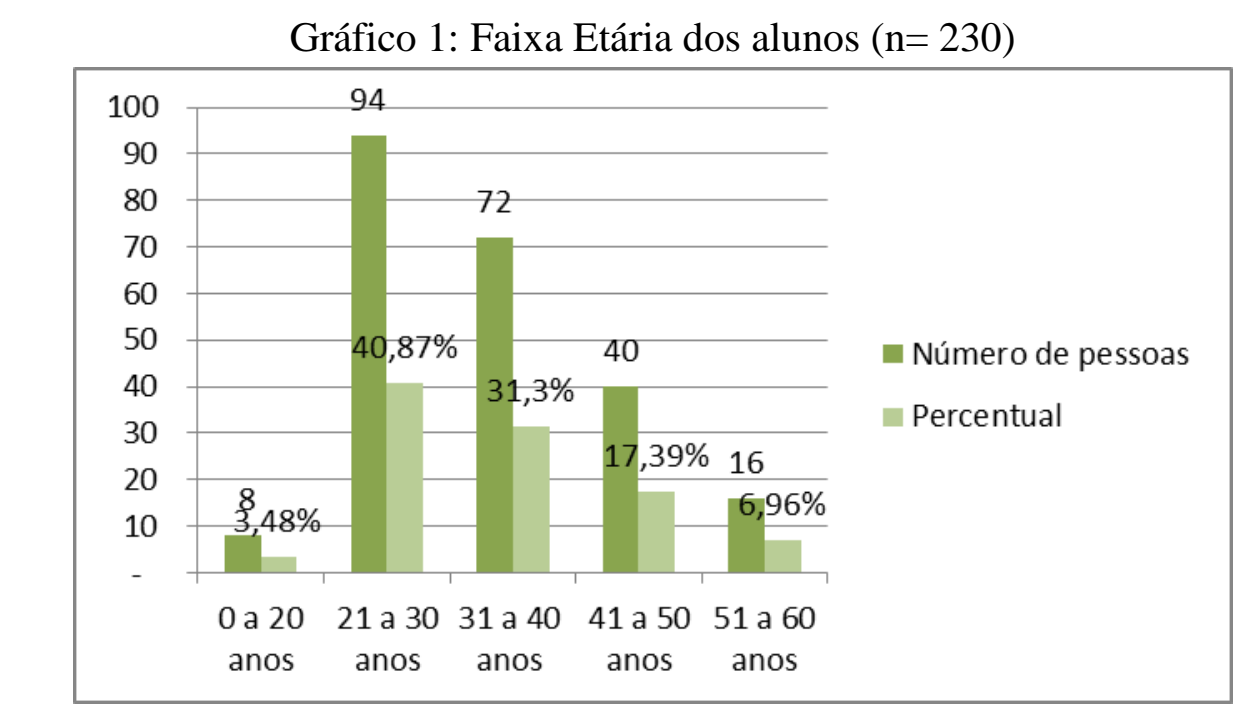

Fonte: Dados organizados pelos autores (2015).

Inclusive, o que se observa é que na agricultura familiar a sucessão das propriedades, tradicionalmente, fica a cargo do filho homem. Nesse sentido, constata-se que essa predominância de homens no curso pode estar relacionada também com o processo de masculinização no campo, conforme será abordado nas análises que seguem. Por outro lado, não se pode descartar também a hipótese de que ainda existe uma invisibilidade da mulher no meio rural, pois se percebe, por observações pessoais, que ela também desempenha muitas das atividades agrícolas ao lado do seu marido ou juntamente com seus pais.

Gráfico 2: Gênero dos alunos participantes do curso (n=230) 

MUNICÍPIOS DE CANGUÇU E DE SÃO LOURENÇO DO SUL - RIO GRANDE DO SUL

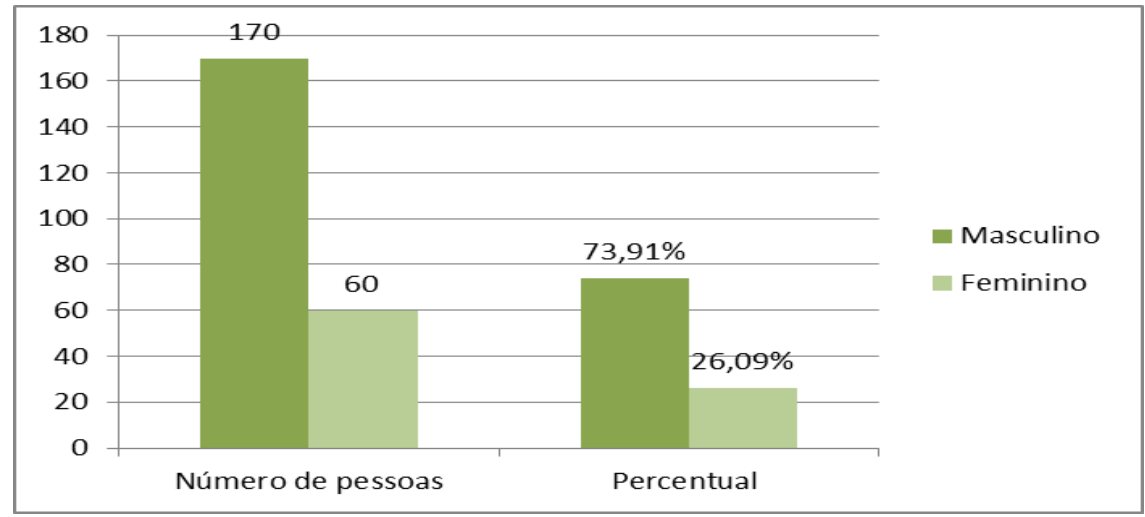

Fonte: Dados organizados pelos autores (2015).

A análise das fichas de matrículas dos alunos evidencia que há pouca procura pelo curso por alunos de diferentes etnias que vivem na região, como sujeitos de cor preta, pardos ou índios, os quais deveriam ser o público-alvo do curso em Agricultura na modalidade a Distância, considerando-se que o referido curso foi criado com o objetivo de beneficiar alunos que vivem no meio rural e que apresentam condição socioeconômica menos favorecida. Conforme pode ser identificado no Gráfico 3, do total de 230 alunos matriculados, 222 são brancos $(96,50 \%), 6$ são negros $(2,70 \%)$, um se declarou como pardo $(0,45 \%)$ e um como índio $(0,45 \%)$.

Gráfico 3: Etnia dos alunos matriculados nos polos de Canguçu e de São Lourenço do Sul $(n=230)$

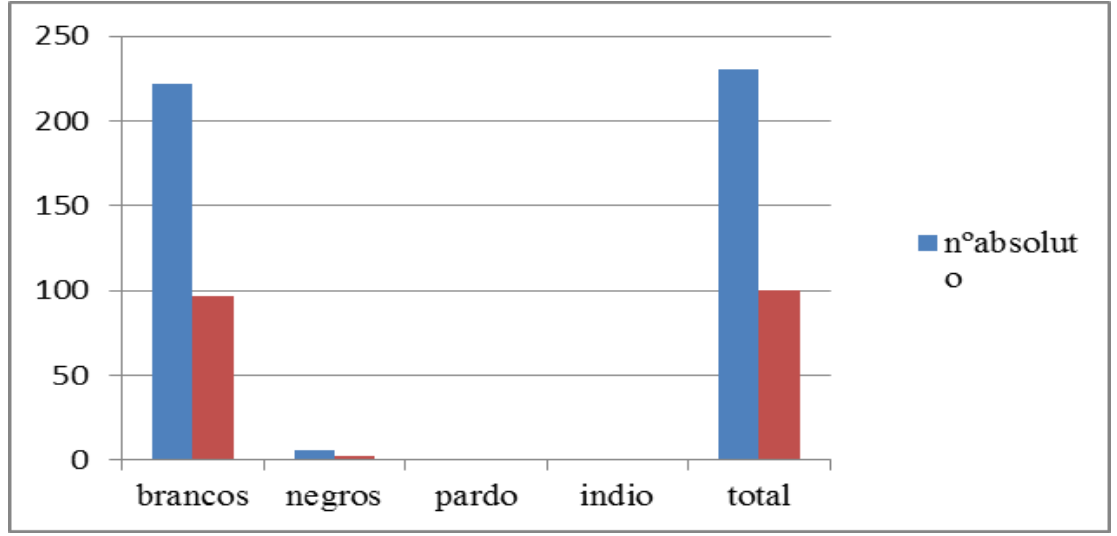

Fonte: Dados organizados pelos autores (2015).

A partir dos dados do IBGE (2010) se constata que há uma predominância das populações no meio rural, tanto no município de Canguçu como no de São Lourenço do Sul. A população total no município de Canguçu, no período de 1991 a 2010, cresceu de forma pouco significativa; entretanto, se observa que os habitantes que vivem no meio rural se tornaram menos expressivos no período analisado, pois em 1991 eles representavam 72,58\% 
LOEBLER, L. B.; KIST, R. B. B.; DEPONTI, C. M.; CADONÁ, M. A.

do total de habitantes do município e em 2010 esse percentual reduziu para 63,02\%, contrastando com o percentual de $27,42 \%$ da população do meio urbano que havia em 1991 e que aumentou para 36,98\% da população total no ano de 2010.

Já a população do município de São Lourenço do Sul, no mesmo período analisado (1991-2010) cresceu de forma pouco significativa, se comparada com o município de Canguçu. Por outro lado, se identifica uma perda significativa da população que vive no meio rural, pois em 1991 a mesma representava um percentual de 54,09\% do total de habitantes de São Lourenço do Sul, valor que reduziu para 43,78\% no ano de 2010. Já a população urbana aumentou de $45,91 \%$ para $56,22 \%$ da população total durante o mesmo período analisado (IBGE, 2010).

Observa-se também um processo de masculinização da população no meio rural, o que pode ser ocasionado pelo êxodo rural da população feminina. Em Canguçu existem mais homens do que mulheres, sendo a população composta de $49.57 \%$ de mulheres e $50.43 \%$ de homens, segundo (IBGE 2010).

Outra questão a ser destacada a partir da análise das fichas de matrículas é o fato de ter havido somente a inclusão de seis alunos de cor preta e um de cor parda, mesmo existindo nos municípios analisados pessoas descendentes de quilombos e de escravos que habitavam a região. Da mesma forma, identificou-se a existência de somente um aluno de origem indígena nos cursos.

Nos que se refere aos 22 alunos entrevistados, identifica-se que treze deles $(59,1 \%)$ possuem filhos, que variam de um a três filhos por família. Esses dados reafirmam o perfil do aluno dos cursos técnicos EAD apresentado pela Associação Brasileira de Educação a Distância (2007), na qual esses sujeitos identificam nessa modalidade uma oportunidade de adquirir o conhecimento sem precisar se distanciar de sua família.

\section{RESULTADOS ${ }^{6}$ DO CURSO NA VIDA DOS ALUNOS E DE SUAS FAMÍLIAS}

A análise sobre os resultados do Curso em Agricultura na modalidade a Distância para a vida dos alunos e de suas famílias teve como base algumas questões relacionadas a sua ligação com a agricultura durante o processo de formação, a aplicação dos conhecimentos

\footnotetext{
${ }^{6}$ Visando garantir o sigilo com relação aos sujeitos entrevistados, a referência às entrevistas ocorrerá através de letras seguidas de números. Dessa forma, para as entrevistas dos Professores será utilizada a letra "P" seguida de números ( $\mathrm{P} 1, \mathrm{P} 2, \mathrm{P} 3 \ldots)$; para os coordenadores e supervisores pedagógicos será utilizada a letra "C" e para os tutores presenciais e a distância será utilizada a letra "T", também seguida de números; e para os alunos será utilizada a letra "A", seguida de números.
} 
adquiridos durante o curso e as percepções dos mesmos sobre a importância do curso para suas vidas, conforme segue.

No que se refere à relação existente entre o Curso em Agricultura com a atividade profissional exercida pelos alunos, constata-se que a maioria deles (quatorze alunos) revelou possuir alguma relação com a atividade agrícola, seja a partir de sua família ou de seu trabalho, conforme pode ser observado nos relatos que seguem.

Sim, meus pais são produtores e meu irmão que ajuda na propriedade. Fui criado para fora e tenho conhecimento sobre as atividades agrícolas. ( $A$. 8).

Sim, sou produtora rural. Plantamos soja, arroz, milho e criamos gado, além da produção para o consumo familiar como a horta e o pomar. ( $A$. 15).

Apenas dois alunos entrevistados revelaram não atuarem na área do curso, apesar de suas famílias permanecerem na área rural. Entretanto, seis deles revelaram que, embora não estivessem atuando no momento das entrevistas, possuem interesse em atuar na área da agricultura assim que concluírem o curso, conforme pode ser evidenciado através de um dos relatos: "Eu tinha conhecimento em agricultura por causa do trabalho na família. Plantamos fumo durante nove anos. Quero investir em fruticultura. A minha família, os meus irmãos, já deixaram a propriedade, mas eu quero ficar”. (A. 22).

Estes dados revelam que, em geral, os alunos possuem condições de partilhar os conhecimentos adquiridos no curso em Agricultura junto às suas famílias e com outros produtores rurais. Quando questionados sobre as formas de aplicação dos conhecimentos obtidos no curso somente dois alunos revelaram que ainda não estão realizando esse processo. Entretanto, os demais afirmaram que o aproveitamento dos conteúdos está sendo concretizado nas suas propriedades e nas de suas famílias, conforme pode ser observado nos relatos que seguem:

Sim, algumas coisas eu consegui implantar na propriedade, principalmente os cuidados ambientais, a utilização de maquinários, o pomar, as pastagens. Fiz estágio na propriedade (A. 6.).

Sim, estou aplicando na minha propriedade, quero continuar atuando nela, apesar de saber das dificuldades do setor principalmente o efeito do clima. (A. 15). 
LOEBLER, L. B.; KIST, R. B. B.; DEPONTI, C. M.; CADONÁ, M. A.

No que se refere à importância do curso para a vida dos alunos, identifica-se que o mesmo possibilita inúmeros benefícios, tanto no aspecto pessoal como profissional. Vários alunos ressaltaram que o curso possibilitou novas formas de relação, aprendizado, novos conhecimentos e a oportunidade de uma qualificação profissional, embora alguns deles não estivessem atuando diretamente na área durante a realização do curso.

A maioria dos alunos entrevistados revelou que sua opção pelo Curso em Agricultura na modalidade a Distância ocorreu em função de que eles já atuavam na área agrícola e sentiram necessidade de uma qualificação visando ao aprimoramento de suas propriedades, conforme pode ser constatado através de algumas respostas que seguem.

\footnotetext{
Adquiri novos conhecimentos, a tecnologia tem avançado ano a ano, e 0 produtor tem que acompanhar isso. (A. 11).

Senti a necessidade de melhorar a propriedade e retornei à escola após 20 anos afastada. Busquei conciliar a realização profissional e pessoal. Tenho gosto pelo estudo e vontade de aprender. Vou continuar fazendo cursos. (A. 15).

Como moro na zona rural e trabalhamos com gado leiteiro, pensei em fazer um curso técnico em agricultura como uma forma de trazer novas informações para o nosso trabalho. (A.16).
}

Através do curso foram proporcionadas aos alunos novas perspectivas de vida, pois eles vislumbram, a partir da formação recebida, além de qualificação das propriedades das famílias, uma oportunidade de ascensão profissional, na medida em que se sentem aptos a prestarem concursos e a realizarem um curso superior, conforme ressaltado por um dos entrevistados:

Esse curso me objetivou a melhorar a propriedade dos meus pais e a conseguir um emprego, e desse emprego, ter condições de buscar uma faculdade. (A.2).

A seguir apresentam-se alguns elementos sobre o curso a distância analisado e sua relação com o desenvolvimento da agricultura dos municípios de Canguçu e de São Lourenço do Sul.

\section{O CURSO A DISTÂNCIA E O DESENVOLVIMENTO RURAL EM CANGUÇU E SÃO LOURENÇO DO SUL}

Os municípios de São Lourenço do Sul e de Canguçu apresentam uma forte presença da agricultura familiar, inclusive, Canguçu é considerado como o município brasileiro com maior número de minifúndios, sendo chamado de "capital nacional da agricultura familiar". 

MUNICÍPIOS DE CANGUÇU E DE SÃO LOURENÇO DO SUL - RIO GRANDE DO SUL

Compreende-se por agricultores familiares aqueles sujeitos que possuem algumas características específicas, tais como:

[...] a propriedade de um pequeno lote de terra, o uso predominante do trabalho da família na execução das tarefas produtivas, o acesso à terra mediante herança, a manutenção dos vínculos sociais assentados em relações de parentesco, entre outras. (SCHNEIDER; NIEDERLE, 2008, p. 989).

No Brasil, a expressão "agricultura familiar"” ganhou projeção nacional no final dos anos 1980 e, principalmente, a partir da primeira metade da década de 1990. O debate, inicialmente, concentrou-se no campo político e, posteriormente, acadêmico (SCHNEIDER, 1999). Se comparada ao debate existente na Europa e nos Estados Unidos, constata-se que essa discussão sobre a agricultura familiar no Brasil ainda está atrasada. No entanto, na América Latina, o Brasil é o país onde esta questão tem gerado muitas discussões e, até mesmo, controvérsias. A própria utilização da expressão "agricultura familiar" não é um consenso entre os autores que estudam o tema, tais como Wanderley (1995; 2003), Tedesco (1999), Graziano da Silva (1999), Neves (1995), Schneider (2003), dentre outros. Contudo, acredita-se que se está tratando de uma mesma categoria social. Assim, constata-se que a compreensão da agricultura familiar como uma categoria social não permite a construção de uma Teoria Social, mas, sim, de uma perspectiva e/ou abordagem teórica que busca a compreensão da realidade e, à medida que se aproxima da mesma, torna-se mais forte e preponderante (DEPONTI, 2008).

Nesse sentido, Ploeg (2014) salienta a dificuldade de compreensão da agricultura familiar, devido a sua contradição com a lógica burocrática, com os protocolos formalizados e com a lógica industrial dominante. $\mathrm{O}$ autor afirma que é difícil captá-la e compreendê-la em sua essência, porque é um fenômeno complexo e multidimensional. A importância da agricultura familiar para o desenvolvimento regional, de acordo com Deponti (2014) vai muito além da produção de alimentos, pois a família controla os principais recursos da propriedade, a saber: a terra, os animais, os cultivos, o material genético, as construções, a maquinaria e o conhecimento de como combinar e utilizar esses recursos.

De acordo com Nierdele e Grisa (2008, p. 44) a compreensão da diversidade produtiva da agricultura familiar pode ser entendida como uma "complexa articulação entre as distintas

\footnotetext{
7 Para ser classificado como de agricultura familiar no Censo Agropecuário de 2006, o estabelecimento precisava atender às condições detalhadas na Lei $\mathrm{n}^{\mathbf{0}} 11.326$, de 24 de junho de 2006. A definição que trouxe a Lei $\mathrm{n}^{\mathrm{o}} 11.326 / 96$ e a inclusão da agricultura familiar nas estatísticas oficiais do IGBE, a partir de 2006, possibilitou dimensionar com mais clareza a sua importância econômica e social (GOMES, 2014).
} 
LOEBLER, L. B.; KIST, R. B. B.; DEPONTI, C. M.; CADONÁ, M. A.

formas familiares que co-habitam os espaços rurais, com suas múltiplas estratégias de reprodução, com os diferentes atores sociais com os quais interagem".

A heterogeneidade social é uma característica dos contextos e das regiões em que a agricultura familiar está inserida. Ploeg (1993), embora não tenha problematizado o componente territorial do conceito de estilos de agricultura, conforme realizado por Schneider e Niederle (2008), analisou a lógica produtiva e social das unidades familiares. De acordo com os autores supracitados, sinteticamente, pode-se afirmar que a diversidade produtiva está relacionada com as diferentes estratégias de reprodução social, econômica e cultural e com os distintos atores sociais que se inter-relacionam (DEPONTI, 2014).

De acordo com Deponti (2014), a heterogeneidade social pode ser observada através das diferentes características territoriais dos espaços onde essa categoria social se apresenta. Portanto, a compreensão dessas características implica o reconhecimento dos diferentes graus de escolaridade, níveis de renda, tamanho das propriedades, formas de composição familiar, formas de manejo da propriedade, entre outros aspectos, evidenciando que não há fórmulas ou receitas prontas para ação, mas a necessidade de construção coletiva por parte dos envolvidos, integrando-os e ressaltando o sentimento de pertencimento nos processos desenvolvidos. Nesse sentido, em contextos de desenvolvimento rural/regional, a heterogeneidade deve ser vista como uma potencialidade e não como um problema (ARAÚJO, 2000).

De acordo com Deponti (2014, p. 6):

A agricultura familiar sofreu um processo heterogêneo de diferenciação, adaptando-
se aos novos contextos e revestindo-se de suas raízes e tradições. No entanto, o lugar
da agricultura na sociedade contemporânea ainda está em construção, necessitando
permanentemente de reconhecimento da sociedade e do Estado, além de políticas
públicas que assegurem sua reprodução, valorização e manutenção de seu
patrimônio sociocultural. Além disso, é necessário o reconhecimento do mundo rural
não só pelas atividades produtivas convencionais, mas pela produção de serviços e
de bens não agrícolas.

De acordo com o Censo Agropecuário de 2006 do IBGE, a agricultura familiar ${ }^{2}$ tem apresentado importância na produção de alimentos, sendo responsável por $87 \%$ da produção nacional de mandioca, por $70 \%$ da produção de feijão, por $46 \%$ do milho, por $38 \%$ do café, por $34 \%$ do arroz, por $21 \%$ do trigo e, na pecuária, por $58 \%$ do leite, por $59 \%$ do plantel de suínos, por 50\% das aves e 30\% dos bovinos (GOMES, 2014).

Em relação ao Valor Bruto da Produção (VBP) no mesmo ano a agricultura familiar correspondia a $38 \%$ do total gerado na agropecuária (R \$ 54 bilhões), sendo os demais $62 \%$ de responsabilidade da agricultura não familiar ( $\mathrm{R} \$ 89$ bilhões). No que se refere às pessoas ocupadas, 74,4\% (12,3 milhões de indivíduos) estavam envolvidas na agricultura familiar no 

MUNICÍPIOS DE CANGUÇU E DE SÃO LOURENÇO DO SUL - RIO GRANDE DO SUL

ano de 2006. Ao mesmo tempo, a agricultura não familiar ocupava 4,2 milhões de pessoas, ou 25,6\% do total das pessoas ocupadas na agropecuária brasileira (STOFFEL, 2013). Essas informações oferecem uma dimensão da importância da agricultura familiar na economia brasileira, bem como para a região analisada.

Considerando-se a realidade dos municípios de Canguçu e de São Lourenço do Sul, ressalta-se a importância da agricultura familiar, pois, de acordo com Graziano (2014, p. 1-2),

Agricultores familiares - e esse grupo inclui produtores de pequeno e médio porte, camponeses, povos indígenas, comunidades tradicionais, pescadores artesanais e muitos outros - detém boa parte da experiência mundial em sustentabilidade, transmitida de geração em geração e aperfeiçoada a ponto de, muitas vezes, conseguir manter a produção mesmo em terras marginais. Foi com base nesse divisor estratégico que as Nações Unidas declararam 2014 o Ano Internacional da Agricultura Familiar. Trata-se de resgatar o duplo potencial que ela encerra de erradicação da fome e conservação dos recursos naturais - elementos centrais do futuro sustentável que se impôs à agenda do século XXI.

Essa predominância da agricultura na região de abrangência do Instituto Federal Farroupilha, Campus de Alegrete, é evidenciada, também, no Plano Político Pedagógico do Curso em Agricultura da modalidade a distância, justificando, inclusive, as vantagens da oferta do referido curso devido às seguintes razões:

a) disponibilidade de infraestrutura física e de recursos humanos para o desenvolvimento e aplicabilidade dos currículos; b) garantia de clientela escolar, considerando a demanda crescente de alunos para os cursos técnicos subsequentes e tecnológicos (ou cursos de nível superior); c) oportunidade de colocação dos egressos do Curso no mercado de trabalho da região; d) necessidade verificada no mercado de trabalho, de profissionais qualificados nas áreas de Informática e Agropecuária. (INSTITUTO FEDERAL DE EDUCAÇÃO, CIÊNCIA E TECNOLOGIA FARROUPILHA, 2013, p. 4).

Nessa perspectiva o desenvolvimento rural apresenta-se complexo, um fluxo de atividades ao longo do tempo que seguem constantemente mudando. A sua natureza, portanto, é de mudança, pois essa mudança é modelada, formada e remodelada na prática. Assim, para uma mesma pergunta podem aparecer respostas novas com o tempo. $\mathrm{O}$ desenvolvimento rural é construído passo a passo, de forma lenta e processual. Os processos de desenvolvimento rural vão, progressivamente, se desdobrando com o passar do tempo. Eles remodulam as práticas agrícolas, uma vez que essas mudanças serão parciais, desiguais e diferenciadas, contribuindo para que seja ampliada a heterogeneidade (VENTURA; PLOEG, 2010; DEPONTI, 2014).

Nesse sentido, constata-se que o Curso em Agricultura na modalidade a distância, integrante da Rede e-Tec, desenvolvido pelo Instituto Federal Farroupilha, através do Campus de Alegrete e dos Polos de Canguçu e de São Lourenço do Sul, constitui-se como uma 
LOEBLER, L. B.; KIST, R. B. B.; DEPONTI, C. M.; CADONÁ, M. A.

estratégia importante de política pública educacional que "visa à oferta de educação profissional e tecnológica a distância e tem o propósito de ampliar e democratizar o acesso a cursos técnicos de nível médio, públicos e gratuitos, em regime de colaboração entre União, estados, Distrito Federal e municípios" (MINISTÉRIO DE EDUCAÇÃO E CULTURA, 2014).

Nessa perspectiva, o público alvo do curso constitui-se basicamente por sujeitos que possuem ligação com o meio rural e com a agricultura familiar, o que comprova a importância do referido curso para os municípios de Canguçu e de São Lourenço do Sul. O curso técnico em Agricultura possibilita a formação profissional desses sujeitos que vivem nos municípios de Canguçu e de São Lourenço do Sul, pois a partir da formação eles se tornam aptos a atuarem de forma mais qualificada em suas propriedades, além de vislumbrarem o acesso a um curso de nível superior, conforme pode se observar através de algumas narrativas.

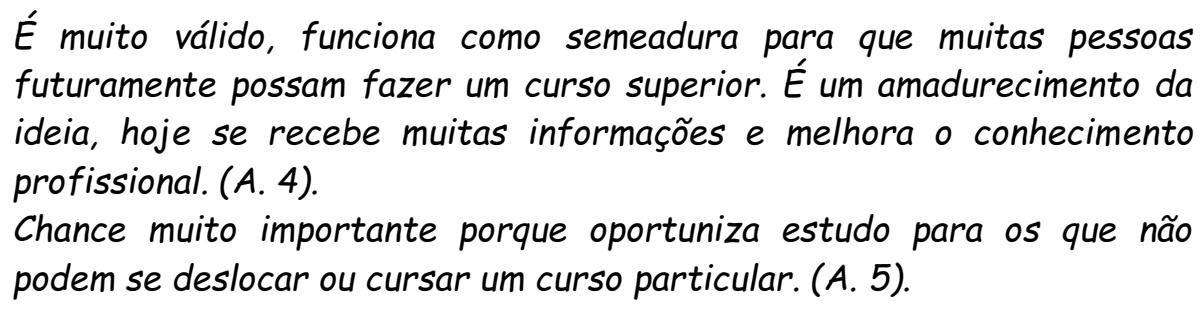

Uma compreensão mais ampla de desenvolvimento considera o curto e o longo prazo, não se atendo apenas as questões econômicas, como retorno e renda, mas também às questões ambientais, especialmente a manutenção do agroecossistema. Assim, destaca-se a importância de serem estudadas também as questões sociais e os conflitos de interesse existentes na região, o que deveria ser contemplado no Curso de Agricultura.

Nesse sentido, os alunos reconhecem também a importância do governo municipal no processo de implantação do curso, especialmente através da disponibilização de infraestrutura necessária nos Polos localizados nos municípios de Canguçu e de São Lourenço do Sul, conforme ressaltado por alguns dos entrevistados:

Avalio como uma iniciativa boa. É uma possibilidade de acesso dos jovens ao estudo. Os jovens que saem da propriedade não retornam a esta. Deveria ser implantado desde o ensino fundamental para incentivar 0 aluno filho de produtor a fazer cursos nesta área. $O$ Polo recebe do governo municipal todo apoio para o funcionamento dos cursos, mesmos nas trocas de gestão o polo continuou evoluindo e crescendo. (A. 17). 
Percebe-se, ainda, que muitos dos alunos revelam que as oportunidades de estudo são oferecidas para todos os sujeitos, especialmente os "menos favorecidos", sendo que, aqueles que não estudam não o fazem porque não querem. Entretanto, há que se considerar que nem todos os sujeitos possuem realmente o acesso ao curso, embora muitos deles atendam aos critérios e às exigências para o ingresso, como ter estudado em escola pública, possuir renda familiar de até um salário mínimo e meio, possuir etnia negra, indígena e/ou parda ou apresentar algum tipo de deficiência física.

Tendo-se presente que os alunos entrevistados revelaram que obtiveram informação sobre o curso através da divulgação realizada nos Polos, através do site do Instituto Federal Farroupilha, através de alunos do curso e de profissionais, além da divulgação nos meios de comunicação local, especialmente rádio e pelo site das Prefeituras Municipais de Canguçu e de São Lourenço do Sul, pode-se concluir que muitos alunos que realmente se encontram em uma situação menos favorecida e que seriam considerados como "público alvo" do curso, nem mesmo tiveram informação sobre a existência do mesmo.

Quando questionados se recomendariam o curso para outras pessoas do município e da região, os alunos entrevistados revelaram, em sua totalidade que sim, pois, segundo eles, são inúmeros os benefícios relacionados com aspectos que já foram referidos, tais como: a possibilidade de qualificação dos agricultores, das famílias das propriedades; a melhora das condições de vida no meio rural; a diversificação da produção e a redução do plantio de fumo; o desenvolvimento dos municípios e da região.

No que se refere à compreensão dos alunos sobre o desenvolvimento da agricultura nos municípios de Canguçu e de São Lourenço do Sul, percebe-se que a maioria deles reconhece a importância que o setor agrícola possui para os dois municípios e para a região, conforme se evidencia em um dos relatos que segue: "Canguçu tem tradição de região agrícola, mas ela carece de técnicos. Existe campo de trabalho nas propriedades, a agricultura está se modernizando e necessita de técnicos para orientar os produtores". (A. 2).

Por outro lado, muitos alunos reconhecem que ainda há algumas lacunas relacionadas com o desenvolvimento da agricultura nos municípios analisados, pois, segundo ressaltado por um deles: "Falta tecnologias voltadas aos pequenos agricultores, um maior incentivo para a produção de alimentos e a valorização do preço". (A. 11).

\section{CONSIDERAÇOES FINAIS}


LOEBLER, L. B.; KIST, R. B. B.; DEPONTI, C. M.; CADONÁ, M. A.

A Educação a Distância pode ser uma das estratégias adotadas para suprir as necessidades de formação de jovens e adultos que vivem no meio rural, tornando-os mais qualificados para o exercício de atividades produtivas no setor agrícola. Entretanto, embora a proposta do Programa e-Tec Brasil seja de democratização do ensino, identifica-se que nem todos os sujeitos que são considerados como "público-alvo" do curso possuem acesso ao mesmo.Além disso, há que se considerar não somente o acesso dos alunos ao curso, mas a garantia de outros elementos que são fundamentais nesse processo, como o acesso às tecnologias de informação, o transporte para seu deslocamento, além da oferta de uma metodologia de ensino que seja compatível com sua realidade. Devem ser consideradas, ainda, as características familiares, culturais, sociais e econômicas desses sujeitos, fatores que são fundamentais para a garantia de que eles possam se manter estudando e obtendo um bom aproveitamento do curso.

Evidencia-se a existência de inúmeros benefícios proporcionados através do Curso em Agricultura na modalidade a distância para os alunos analisados, entretanto, identificam-se alguns desafios que dizem respeito a questões como as dificuldades de adaptação dos alunos à modalidade de ensino a distância; a falta de comunicação entre os alunos e os profissionais decorrentes de fatores como a resistência dos alunos, a falta de respostas dos professores às demandas dos alunos, ou ainda, a falta de acesso à internet no meio rural; a dependência de recursos financeiros do governo federal, o que compromete a disponibilização de material didático em função do atraso dos repasses, evidenciando, também, uma falta de comprometimento do próprio Estado com relação à Educação; falta de qualificação de alguns profissionais e falta de comprometimento de alguns alunos; entre outros aspectos evidenciados.

O curso analisado possui um papel importante no processo de desenvolvimento da agricultura dos municípios analisados, pois possibilita a permanência dos alunos em seus municípios de origem, da qual podem conciliar a família, o trabalho e o estudo; permite o processo de qualificação das propriedades rurais; possibilita a ascensão profissional destes sujeitos através de oportunidades de ingresso no mercado de trabalho (no setor privado e/ou a partir do poder público).

Por fim, considerando-se que, em um contexto de desenvolvimento regional em que a agricultura familiar, além de contribuir para o desenvolvimento dos municípios de Canguçu e de São Lourenço do Sul, possibilita aos agricultores novas possibilidades de produção e de 
reprodução social através da sua diversidade e de sua multifuncionalidade verificada a partir de ações desenvolvidas no território voltadas à agroecologia, à agroindústria, às cadeias curtas, à diversificação produtiva e ao turismo rural, constata-se que o Curso em Agricultura na modalidade a Distância, contribui tanto para a qualificação de seus egressos como para o desenvolvimento rural dos municípios de Canguçu e de São Lourenço do Sul.

\title{
TECHNICAL COURSE IN AGRICULTURE AND RURAL DEVELOPMENT OF CANGUÇU AND ARE SÃO LORENÇODO SUL - RIO GRANDE DO SUL
}

\begin{abstract}
Abastract
This article presents data from a research that aimed to analyze the implications of the Technical Course in Agriculture, part of the program e-Tec Brasil, for the training of farmers and for the development of agriculture in the municipalities of São Lourenço do Sul and Canguçu. It was performed a study of qualitative approach, based on the dialectic critical method. There were semi-structured interviews with 22 students of poles of Canguçu and São Lourenço do Sul and with 19 professionals from the Campus of Alegrete, members of a course in agriculture in the modality of the distance, offered in southern Brazil. It was found that the Agriculture Technician Course in Distance modality plays an important role in development of agriculture of the municipalities analyzed, therefore, enables the students staying in their home municipalities, and contributes for the process of qualification of rural properties; the professional advancement of these individuals through opportunities in the labor market (in the private sector and / or from the government).
\end{abstract}

Keywords: Technical Course in Agriculture; Distance Education; Rural development; Professional qualification; Family Farming 
LOEBLER, L. B.; KIST, R. B. B.; DEPONTI, C. M.; CADONÁ, M. A.

\title{
EL CURSO TÉCNICO A LA DISTANCIA EN AGRICULTURA Y EL DESSARROLLO RURAL DE LOS MUNICIPIOS DE CANGUÇU Y DE SÃO LOURENÇO DO SUL - RÍO GRANDE DEL SUR
}

\begin{abstract}
Resumen
Este artículo tiene como objetivo analizar las implicaciones del Curso Técnico en Agricultura que integra el Programa e-Tec Brasil, para la formación de agricultores y para el desarrollo de la agricultura de los municipios de São Lourenço do Sul y de Canguçu. Se ha realizado un estudio con enfoque cualitativo, con base en el método dialectico crítico, en la cual se han realizado encuestas semiestructuradas con 22 alumnos de los Polos de Canguçu y de São Lourenço do Sul, y con 19 profesionales del Campus de Alegrete, integrantes de un Curso en Agricultura en la modalidad a la distancia, ofertado en la región sur de Brasil. El análisis de los datos ocurrió a través de la técnica de análisis de contenido y de la técnica de tratamiento estadístico sencillo. Se ha constatado que el Curso Técnico en Agricultura en la modalidad a la distancia tiene un importante papel en el proceso de desarrollo de la agricultura de los municipios analizados, pues posibilita la permanencia de los alumnos en sus municipios de origen, el proceso de calificación de las propiedades rurales; la ascensión profesional de los sujetos a través de las oportunidades del ingreso en el mercado laboral (en el sector privado e/o a partir del poder público).
\end{abstract}

Palabras-clave: Curso Técnico en Agricultura; Educación a la Distancia; Desarrollo Rural; Calificación Profesional; Agricultura Familiar

\section{REFERÊNCIAS}

ARAÚJO, Tânia Bacelar de. Ensaios sobre o desenvolvimento brasileiro: Heranças e urgências. Rio de Janeiro: Revan, 2000.

BRASIL. Constituição Federal (1988). Disponível em:

<http://www.dji.com.br/constituicao_federal/cf205a214.htm>. Acesso em: 30 mar. 2015.

Congresso Nacional. Lei de Diretrizes e Bases da Educação Nacional: LDB

9394/96. Brasília: Congresso Nacional, 1996. 
O CURSO TÉCNICO A DISTÂNCIA EM AGRICULTURA E O DESENVOLVIMENTO RURAL DOS MUNICÍPIOS DE CANGUÇU E DE SÃO LOURENÇO DO SUL - RIO GRANDE DO SUL

Decreto $\mathrm{n}^{\circ}$ 5.800, de 08 de junho de 2006. Disponível em:

$<$ http://uab.capes.gov.br/index.php?option=com_content\&view=article\&id=60:decreto-no5800-08062006-decreto\&catid=14:decretos\&Itemid=44>. Acesso em: 23 de mar. 2013.

Lei $\mathrm{n}^{\circ}$ 11.892, de 29 de dezembro de 2008. Disponível em:

<http://www.planalto.gov.br/ccivil_03/_Ato2007-2010/2008/Lei/L11892.htm >. Acesso em: 20 de mar. de 2015.

Decreto $\mathrm{n}^{\circ}$ 5.622, de 19 de dezembro de 2005. Disponível em: <portal.mec.gov.br/seed/arquivos/pdf/dec_5622.pdf >. Acesso em mar.2013.

Decreto $\mathrm{n}^{\circ} 7.589$, de 26 de outubro de 2011. Disponível em:

<www.planalto.gov.br/..._Ato2011-2014/2011/Decreto/D7589.htm> Acesso em: fev. 2015.

CONTERATO, M; SCHNEIDER, S.; WAQUIL, P. Estilos de agricultura: uma perspectiva para a análise da diversidade da agricultura familiar. Ensaios FEE, Porto Alegre, v. 31, n. 1, p. 149-186, 2010.

DEPONTI, Cidonea Machado. As "agruras" da gestão da propriedade rural pela agricultura familiar. In: REDES, Revista do Desenvolvimento Regional, Santa Cruz do Sul: Universidade de Santa Cruz do Sul, v. 19, ed. especial, p. 9-24, 2014.

- Contribuições teóricas brasileiras ao debate da agricultura familiar. In: Revista Gedecon, v. 2, p. 82-102, 2008.

GOMES, A. A operacionalização do mercado institucional de alimentos no contexto do Vale do Rio Pardo: o caso da Cooperativa Leoboqueirense de agricultores familiares. 2014. $133 \mathrm{f}$. Dissertação (Programa de Pós Graduação em Desenvolvimento Regional). UNISC: Santa Cruz do Sul.

SILVA, J. G. Não há nada mais avançado do que o potencial da agricultura familiar. 2014. Disponível em: <www.mst.org.br/node/15565>. Acesso em: 06 de mai. 2014.

INSTITUTO BRASILEIRO DE GEOGRAFIA E ESTATÍSTICA (IBGE). Censo demográfico 2010. Banco de dados agregados do IBGE. Disponível em: <http://www.sidra.ibge.gov.br/cd/cd2010ETRD.asp>. Acesso em: 10 de mar. 2015.

INSTITUTO FEDERAL DE EDUCAÇÃO, CIÊNCIA E TECNOLOGIA FARROUPILHA. Plano de Desenvolvimento Institucional do IF Farroupilha - 2009 -2013. Disponível em: <http://www.iffarroupilha.edu.br/site/>. Acesso em: 12 out. 2014.

INSTITUTO FEDERAL DE EDUCAÇÃO, CIÊNCIA E TECNOLOGIA DO RIO GRANDE DO SUL. Apresenta informações gerais sobre a instituição. Disponível em: <http://www.ifrs.edu.br/site>. Acesso em: 10 de dez. 2014.

MINISTÉRIO DA EDUCAÇÃO E CULTURA. Polo de Educação a Distância 2015. Disponível em: <http://portal.mec.gov.br/component/content/article?id=12824:o-que-e-umpolo-de-educacao-a-distancia>. Acesso em: 15 de mar. 2015. 
LOEBLER, L. B.; KIST, R. B. B.; DEPONTI, C. M.; CADONÁ, M. A.

Rede e-Tec Brasil: Apresentação. 2014. Disponível em:

<http://portal.mec.gov.br/rede-e-tec-brasil>. Acesso em 16. jun. 2015.

NEVES, D. Agricultura familiar: questões metodológicas. Revista Reforma Agrária, Campinas, v. 25, n. 2 - 3, p. 21-37, maio/dez., 1995.

NIERDELE, P. A.; GRISA, C. Diversificação dos meios de vida e acesso a atores e ativos: uma abordagem sobre a dinâmica de desenvolvimento local da agricultura familiar.

Cuadernos Desarrollo. Rural, Bogotá Colombia, 2008, p. 41-59.

PLOEG, Jan Douwe Van Der. Rural sociology and the new agrarian question: a perspective from the Netherlands. Sociologia Ruralis. v. 32, n, 2, p. 240-246, 1993.

Diez calidades de la agricultura familiar. Disponível em:

<http://www.agriculturesnetwork.org/magazines/latin-america/agricultura-familiarcampesina/diez-cualidades-de-la-agricultura-familiar\#.UuUwcJwo1EM.email>. Acesso em: 22 de maio. 2014.

SCHNEIDER, S.; NIEDERLE, P. A. Agricultura familiar e teoria social: a diversidade das formas familiares de produção agrícola. In: FALEIRO, F. G.; FARIAS, NETO, A.L. (Orgs.). Savanas: desafios e estratégias para o equilíbrio entre sociedade, agronegócio e recursos naturais. Planaltina, DF: Embrapa Cerrados, 2008.

SCHNEIDER, S. Teoria social, agricultura familiar e pluriatividade. Revista Brasileira de Ciências Sociais, São Paulo: Associação Nacional de Pós-Graduação e Pesquisa em Ciências Sociais, v. 18, n. 51, p. 99-123, 2003.

STOFFEL, Janete. A influência da Agricultura Familiar no desenvolvimento rural na região Sul do Brasil. 2013. 291 f. Dissertação (Doutorado Desenvolvimento Regional) Universidade de Santa Cruz do Sul: Santa Cruz do Sul.

TEDESCO, J. C. Terra, trabalho e família: racionalidade produtiva e ethos camponês. Passo Fundo Ed. UPF, 1999.

VENTURA, F.; PLOEG, J. D. V. D. Rural development: some tentative conclusions. Rivista di Economia Agraria. Anno LXV, n. 2, giugno 2010. A comparative analysis of rural development processes in China, Brazil and the European Union, 378 p. 319-336.

WANDERLEY, M. N. B. A Agricultura familiar no Brasil: um espaço em construção. Revista da ABRA, Associação Brasileira da Reforma Agrária, v. 25, n. 2/3, Mai-Dez, 1995. 